Мятишкин Юрий Владимирович

старший инженер ИПУСС РАН — СамНЦ РАН

e-mail: myat2008@mail.ru

\title{
ФОРМИРОВАНИЕ СИСТЕМЫ УПРАВЛЯЕМОГО САМОУПРАВЛЕНИЯ В МНОГОКВАРТИРНЫХ ДОМАХ
}

Аннотация. Либерализация системы ЖКХ создала вакуум социальной ответственности: власти сложили ее с себя на граждан, а те, в свою очередь, ответственность за общее имущество не приняли. В результате у новых собственников многоквартирных домов возникли существенные искажения в экономических отношениях с поставщиками услуг и ресурсов для нужд проживания в доме. В связи с этим существует необходимость в новых подходах в организации местного самоуправления.

Ключевые слова: самоуправление, патернализм, подталкивание, ЖКХ

Тематический рубрикатор e-Library: 06.56.31

\author{
Yuri V. Myatishkin
}

senior engineer, Institute for the Control of Complex Systems of Russian Academy of Sciences

\section{FORMATION OF MANAGED SELF- GOVERNMENT SYSTEM IN APARTMENT BUILDINGS}

Abstract. The liberalization of the housing and utilities systems created vacuum of social responsibility: the authorities laid it on the citizens, and they, in turn, did not accept responsibility for the common property. As a result, new owners of apartment buildings have experienced significant distortions in their economic relations with providers of services and resources for the needs of living in the house. In this regard, there is a need for new approaches in the organization of local self-government.

Keywords: self-government, paternalism, pushing, housing and utilities

Современными авторами общественное самоуправление, гражданское общество принимаются как общественный институт проявления личной активности граждан, когда те по своей инициативе и своими силами решают свои общественные, социальные проблемы [2,3]. Это состояние противоположно патерналистическому обществу.

Основной причиной низкой гражданской активности большое число исследователей видит в стереотипах общественного поведения, сформированных монархическим и далее советским образом жизни, подразумевающих централизованное подчинение и низкий уровень самостоятельности. 
Низкая готовность граждан брать на себя ответственность за свою судьбу, перекладывание вины за имеющиеся проблемы на начальство (государство) являются причиной невысокого качества труда, бедности и низкого уровня гражданских прав.

Патернализм - это проблема не только граждан, но и власти и бизнеса, так как является причиной низкой эффективности общественной экономики и, соответственно, веса на международной арене, недоверия к представителям власти в самом обществе. Слабая экономическая активность граждан обуславливает невысокую инвестиционную привлекательность в новые хозяйственные темы и, как следствие, низкий уровень налогооблагаемой базы.

На практике принятие ответственности проявляется как принятие решения с последующей его реализацией. Соответственно, побуждая граждан принимать подготовленные проекты решений, которые они способны сообща редактировать, власти могут таким образом подталкивать людей к принятию ответственности. Самостоятельное или полусамостоятельное разрешение проблемных ситуаций позволит гражданам точнее удовлетворять свои интересы, чем это могло бы быть сделано без их участия.

Наиболее удачным местом приложения такой практики, с нашей точки зрения, является система управления общим имуществом многоквартирных домов (МКД). Научив и приучив граждан к необходимости ведения общедомового хозяйства, можно распространить этот опыт и на другие сферы жизни, сделав систему помощи в принятии групповых совместных решений неотъемлемой частью развития общественной экономики.

Статьей 44 Жилищного кодекса РФ обозначен широкий список прав общего собрания собственников помещений в многоквартирном доме. Данным положением однозначно задается определяющая роль общего собрания собственников (ОСС) МКД в вопросе управления общим имуществом дома.

Однако для практической реализации данного права необходимо проводить немалую работу по организации принятия решений общими собраниями (рис.1). 


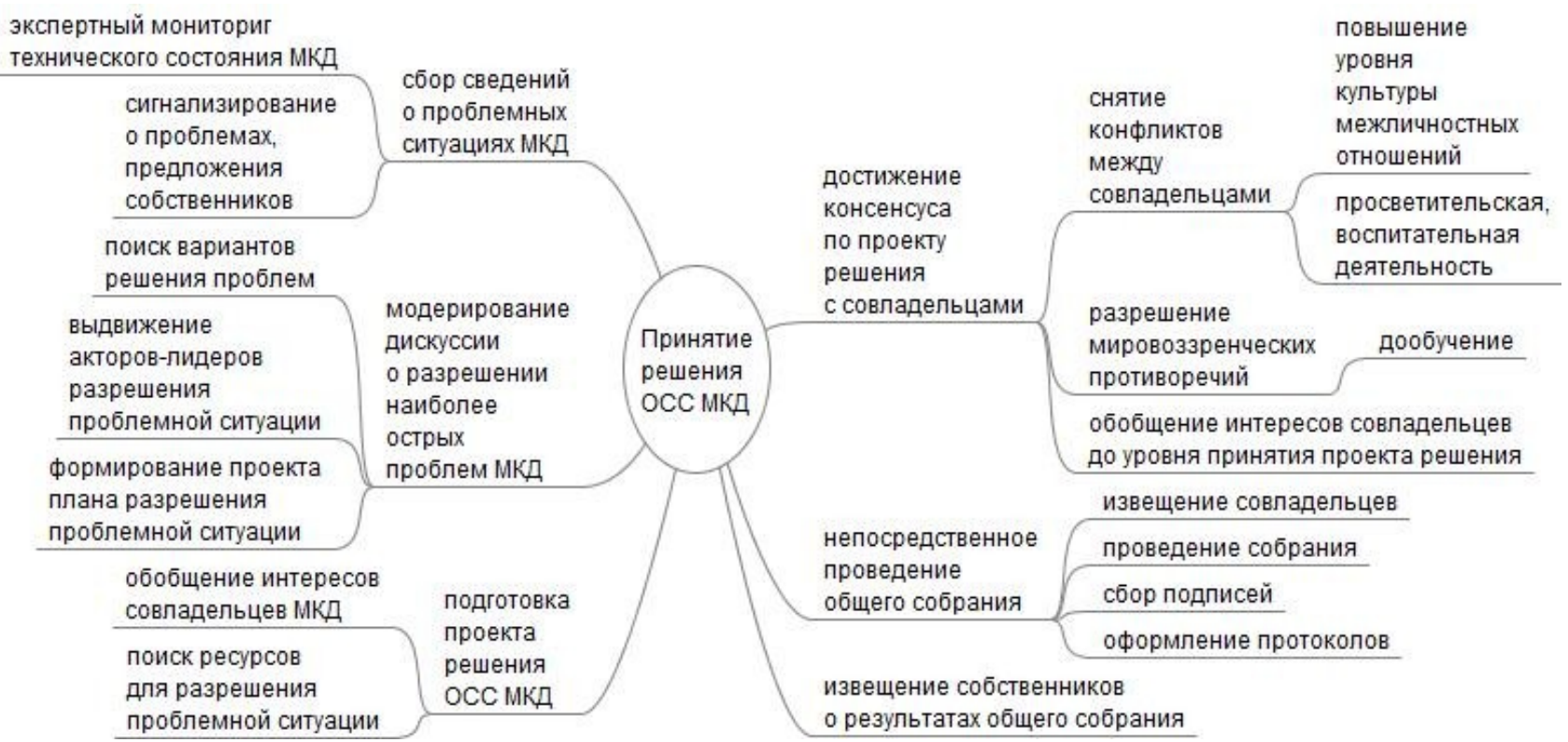

Рис. 1 Работа организаторов принятия решения общего собрания собственников МКД

Сегодня гражданами все это отдается на откуп активистам-добровольцам, председателям ТСЖ или УК, которые эту работу проводят формально и не во всех предусмотренных законодательством случаях.

Если организатор принятия решения (заказчик) и исполнитель работ являются одним и тем же лицом (ТСЖ и УК), то очень высока вероятность искажения истинных интересов собственников МКД, нарушения их прав. Если собственниками отдельно не оплачивается работа активистов по принятию решения ОСС МКД, то они заинтересованы удовлетворять свои личные интересы в первую очередь, а не общественные, что тоже является источником нарушения прав совладельцев МКД.

Однако сегодня среди внушительного числа совладельцев нет готовности не то чтобы оплачивать работу по организации принятия решения общим собранием, большинство сегодня в принципе уклоняется от обязанности вести общедомовое хозяйство, не желая принимать за него ответственность.

Чтобы преодолеть эту проблему, необходимо осуществить весьма ощутимые вложения в формирование стереотипов совместного ведения общего хозяйства [1]. Полное самофинансирование этого процесса упирается во все ту же проблему нежелания принимать ответственность гражданами, а также их низкую покупательную способность на развитие данных отношений.

В реализацию этой системы кроме граждан могли бы вложить предприниматели, но инвестирование в изменение рынка таким способом сегодня для бизнеса не представляется привлекательным, так как сбыт ему придется осуществлять через слабо управляемые собственниками УК и ТСЖ. 
Поэтому для преодоления проблемы патернализма и инициирования инвестиционной активности в общее хозяйство МКД необходима господдержка процесса полусамостоятельного администрирования.

Его целесообразно осуществить через ТОС посредством субсидирования оплаты работы по предоставлению помощи в организации принятия решения ОСС МКД. Так как жильцам недоступно заниматься технологическим развитием на высоком профессиональном уровне, то работа третьих лиц с жильцами и собственниками МКД при посредничестве ТОС может на постоянной основе стать системой осуществления подталкивания граждан [4] к разрешению своих проблемных ситуаций.

Для увеличения объема финансирования системы принятия решения ОСС МКД целесообразно привлекать не только бюджетные средства, но и деньги бизнеса. Таким образом на дискуссионной площадке ТОС будут учитываться интересы всех сторон общества. Это обеспечит наиболее высокое качество принимаемых решений по развитию общественного хозяйства.

Инициирование данного развития находится в руках действующей власти, так как именно ее больше всего опасаются граждане и бизнес.

Таким образом, трехстороннее финансирование системы местного общественного самоуправления способно помочь:

- преодолеть патерналистические общественные стереотипы и увеличить тем самым полезность общественной экономики для граждан, инвестиционную привлекательность экономики, повысить авторитет власти;

- сформировать новые принципы планирования экономического и общественного развития и повысить эффективность расходования экономических ресурсов в интересах как самих граждан, так и власти и бизнеса.

\section{Библиографический список}

1. Моисеева Т.В., Мятишкин Ю.В. Противодействие правонарушениям посредством внедрения интерсубъективного управления в сообществе собственников многоквартирного дома // Проблемы управления и моделирования в сложных системах: труды ХХ Междунар. конф. - Самара: Изд-во ООО «Офорт», 2018. - 561с. C. $273-278$

2. Полтерович В.М. От социального либерализма к философии сотрудничества / Общественные науки и современность. Российская академия наук - Москва №4 2015г С. 41-64

3. Рой О. М. Трансформация территориального общественного самоуправления в условиях централизации власти вестник сургутского государственного университета // Вестник Сургут. гос. Ун-та. Сургут. 2019. № 1 (23) С. 133-138.

4. Талер Р. Новая поведенческая экономика: почему люди нарушают правила традиционной экономики, и как на этом заработать // М.: Изд-во «Э», 2017. — 368 с 